\title{
Pharmacovigilante's in the Pharmacovigilance Programme of India: Ideal Qualities and Skills
}

\author{
Kalaiselvan Vivekanandan ${ }^{*}$, Prasad Thota' ${ }^{1}$, Vijay Venkatraman Janarthanan ${ }^{2}$, Gyanendra Nath Singh ${ }^{1}$ \\ 'Department of National Coordination Centre for Pharmacovigilance Programme of India, Indian Pharmacopoeia Commission, Ministry of Health \& Family Welfare, \\ Sector-23, Raj Nagar, Ghaziabad-201002, INDIA. \\ 2Managing Director \& CEO, Oviya MedSafe, Pharmacovigilance Consulting \& Drug Safety Services, Coimbatore, India \& London, UK.
}

\begin{abstract}
The PVLs are specialized, trained, and dedicated professional's acting as the main link between patients and healthcare professionals for ensuring better outcome in monitoring the benefit-risk ratio of drugs. This article overviews the functions of PVLs in the context of their roles and responsibilities in the Pharmacovigilance Programme of India.
\end{abstract}

Key word: Pharmacovigilante's, Pharmacovigilance, Pharmacovigilance Programme of India, Drug Safety.

\section{Correspondence :}

Dr. Vivekanandan Kalaiselvan, M.Pharm., Ph.D,

Principal Scientific Officer, Indian Pharmacopoeia Commission,

Ministry of Health and Family Welfare, Govt of India, Sector 23, Raj Nagar,

Ghaziabad-201 002, U.P, INDIA.

Phone no: +911206582849

E-mail: pvpi.ipcindia@gmail.com

DOI: 10.5530/jyp.2016.3.21
There is no drug in the clinical practice without any adverse effects. Paracelsus, the Greek physician and philosopher (also known as the father of toxicology) had stated in the fifteenth century, that "All substances are poisons; There is none which is not a poison. The right dose differentiates a poison from a remedy". That statement remains true even today and will continue to be so (till the medical science comes up with ultimate harmless 'utopian drugs'). ${ }^{1}$ Therefore drug safety monitoring has been emerged as one of the important area in patient's care.WHO defines Pharmacovigilance as the science and activities relating to the detection, assessment, understanding and prevention of adverse effects or any other possible drug related problems. The term now also encompasses the problems related to the use of herbals, traditional and complementary medicines (especially relevant to population in our country), blood products, biological, medical devices, and vaccines. ${ }^{2}$ There can be many unexpected events or complications in the clinical practice which might not have been in the list of adverse reactions of a marketed product. This is the limitation of the drug discovery process and is applicable to everything new that is coming in the market and is being prescribed, and this limitation demands the Pharmacovigilante's (PVLs) involvement as a good communicator to prescriber for the product related valuable experience as feedback. PVLs are the professionals engaged in the detection, assessment, understanding, and prevention of adverse drug reactions (ADRs). ${ }^{3}$

The PVLs are specialized, trained, and dedicated professional's acting as the main link between patients and healthcare professionals for ensuring better outcome in monitoring the benefit-risk ratio of drugs. This article overviews the functions of PVLs in the context of their roles and responsibilities in the Pharmacovigilance Programme of India.

Budding PVLs must have qualities to set the highest professionals standards and to bring the phase of transformation in Pharmacovigilance (PV). The PVLs need a degree in medicine, dentistry, pharmacy, nursing, life sciences or other health related field or equivalent qualification to conduct PV activities. They must know the ethics and good PV practices and also should have the basic knowledge of concepts, methodologies of $\mathrm{PV}$, drug regulation etc. so that they can be competent enough on handling the issues like case narrating and processing, causality assessment, identifying new signals, benefit risk assessment. They also should able to understand and device strategies for risk management and risk minimization plan. At the same time, they must act in the interests of the patients by applying their unique skills and knowledge in drug therapy, prescription etc which are well enough to prevent adverse effects. PV is also technology driven because information technology (IT) involved in all most all sections ranging from data entry to signal detection. It is also no secret that IT has merged into clinical safety practice and sparks the creation of worldwide pharmacovigilance systems for safety signal detection. ${ }^{4}$ Therefore, the PVLs should able to apply the IT tools in their practice and also needs to be updated the innovative newer technologies to reach out the messages in rapid and effective way. Since biostatistics \& bio-analytical procedures are integral part of risk management, data mining and signal detection. PVLs should have basic knowledge on these areas.

$\mathrm{PV}$ is one of the professions that require utmost commitment and constant dedication because PVLs are engaged in Patient Safety. Therefore, PVLs always need to put patients before themselves, as any other healthcare professionals would do. They may not be able to stick to the official working hours; they will have to be vigilant round the clock because ADRs may occur beyond working hours too. This necessitates PVLs to work as a coordinated team in a structured and target-oriented manner, which indicates that the operational excellence of the team of PVLs is directly proportional to the performance of the whole unit. PV is the only profession in healthcare that has to coordinate with maximum number of varied stakeholders such as pharmaceutical manufacturers, doctors, pharmacists, nurses, patients, regulators, media etc. ${ }^{5,6}$ Therefore, PVLs should possess strong management and organizational skills also. They should also have capacity to guide junior colleagues and lead the team, while keeping their seniors duly informed of any issue that appears to demand their immediate attention. Since PV involves global networks and as PV activities cannot be limited to one country, PVLs are also required to be updated with national and international drug legislations, PV affairs, industry practices, global trends, etc.

The purpose of PV is defeated if the PVL fails to communicate the findings to the stakeholders on timely basis. For an example the PVL in India should be fluent in English and Hindi too, especially if they are posted in Hindi-speaking states, which account for $41 \%$ population of India. ${ }^{6}$ If PVLs are posted in ADRs monitoring centre of non Hindi speaking states such as Tamil Nadu, Karnataka, Kerala, Andhra Pradesh and 
Telangana etc they must have capacity to understand the respective local languages, in order to communicate with the patients. The PVL should know media ethics while communicating to the Medias. Usually the PVLs working in the system are not supposed to communicate any findings to the media unless otherwise they have been authorized by a competent authority to do speak.

Another important quality is that they should inculcate a practice of sufficient and timely feedback to the stakeholders, besides redefining their expectations in order to take them in to confidence in all PV activities and also to seek their continuous support.

In addition to these, PVLs should have the following qualities to pursue excellence in PV:

a. Creating professional bonding with the stakeholders;

b. Maintaining the amiable relationship with colleagues and similarly placed organizations (both national and international); and

\section{c. Providing innovative ideas in PV}

PVLs should be proud of entering the noble and fulfilling the wonderful profession of PV and for being a partner in public health, by doing best for the prevention of ADRs. PVLs should take this opportunity seriously from their career growth aspect too, which would eventually further enhance India's PV system towards excellence.

\section{ACKNOWLEDGEMENT}

We are thankful to the Indian Pharmacopoeia Commission \& Ministry of Health \& Family Welfare, Government of India for supporting National Coordination Centre-Pharmacovihilance Programme of India.

\section{CONFLICT OF INTEREST}

The author declare no conflict of interest.

\section{ABBREVIATIONS USED}

PV: Pharmacovigilance; PVLs: Pharmacovigilante's; PvPI: Pharmacovigilnace Programme of India; IPC: Indian Pharmacopoeia Commission; ADRs: Adverse Drug Reactions; IT: Information Technology.

\section{ABOUT AUTHORS}

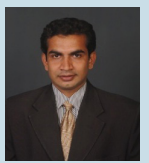

Dr. V. Kalaiselvan: Is Principal Scientific Officer at Indian Pharmacopoeia Commission, Ministry of Health \& Family Welfare, Government of India, Ghaziabad, Uttar Pradesh. He is responsible for coordinating the Pharmacovigilance Programme of India (PvPI), at National Coordination Centre (NCC) and working with different partners in Pharmacovigilance at national and international levels. He has overall responsibility for the technical and operational activities of the PvPI. He has been instrumental in establishing ADRs monitoring centres, helpline for reporting ADRs, PvPI toolkit etc. He has also been actively involved in ISCRs processing and quality review, signal detection and education, training and skill development programs under PvPI. He is serving as the member/member secretary in various committees and panels under PvPI, CDSCO, RNTCP and AEFI.

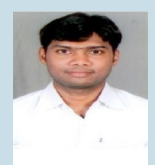

Dr. Prasad Thota: Is Scientific Assistant at Indian Pharmacopoeia Commission, Ministry of Health \& Family Welfare, Government of India, Ghaziabad, Uttar Pradesh. He has overall responsibility for the coordination between ADR monitoring centres \& WHO-Uppsala Monitoring Centre, Sweden for updating, resolving various scientific \& technical related issues. He has also processing ICSRs for various AMCs, assisting in monitoring, organising of Signal, Quality, and Core Training Panel Meetings under PvPI. He is serving as the member secretary in Core Training panel under PvPI.

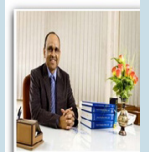

Dr. Gyanendra Nath Singh: Is Secretary cum Scientific Director at Indian Pharmacopoeia Commission, \& Drugs Controller General (India), Central Drugs Standard Control Organisation, Ministry of Health \& Family Welfare, Government of India. He is a recognized research guide in the subject of Pharmaceutics \& Pharmaceutical Sciences. He is serving as the member/member secretary in various committees and panels under IPC, NLEM, PCIM, IEC-NIB, PCI, DTAB, DCC of CDSCO. He has more than 200 scientific publications in this area and made presentations in various National and International conferences in India and overseas.

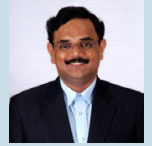

Dr J Vijay Venkatraman: Is a Diabetologist, Drug Safety Physician and Entrepreneur, with 15 years of Clinical and Pharmacovigilance experience. He holds a MBA degree in Services Management. He is the first person hailing from India to be awarded the Fellowship of the Pharmaceutical Information \& Pharmacovigilance Association, United Kingdom.

\section{REFRENCES}

1. Ashok D, Shailendra SH. Are we pharmacovigilant enough in ophthalmic practice. Indian J Ophthalmol. 2013;61(5):226-9.

2. World Health Organization: The Importance of Pharmacovigilance Safety Monitoring of Medicinal Products: 2002. Available from: http://apps.who.int/ medicinedocs/pdf/s4893e/s4893e.pdf [last updated on 29 April 2015]

3. Uppsala Reports 54: July 2011-2: UR54 July 2011. Available from: http://www. who-umc.org/graphics/25223.pdf [last updated on 29 April 2015]
4. Zhengwu Lu. Information technology in pharmacovigilance: Benefits, challenges, and future directions from industry perspectives: Drug, Healthcare and Patient Safety. 2009:135-45.

5. Kalaiselvan V, Kumar R, Singh GN. Indian Pharmacopoeia Commission's Partners for Promoting Public Health. Adv Pharmacoepidemiol Drug Saf 4: 181 doi:10.4172/2167-1052.1000181

6. Jeetu G, Anusha G. Pharmacovigilance: A Worldwide Master Key for Drug Safety Monitoring. J Young Pharm. 2010;2(3):315-20 